\title{
Anatomia do nervo isquiático em mocós (Kerodon rupestris WIED, 1820) aplicada a clínica de animais silvestres
}

Renata Celis dos SANTOS 1 José Fernando Gomes de ALBUQUERQUE²

Márcio César Vasconcelos SILVA ${ }^{3}$

Carlos Eduardo Bezerra de MOURA $^{4}$

Roberto Sergio Nunes

$\mathrm{CHAGAS}^{2}$

Roméria Rodrigues

BARBOSA $^{5}$

Maria Angélica MIGLINO ${ }^{6}$

\section{Correspondência para:}

RENATA CELIS DOS SANTOS

Av. Capitão Francisco Borges de Godoy Macota, 200 - Jardim Nova Aparecida 14883-390 - Jaboticabal/SP

romeriarodrigues@hotmail.com

Recebido para publicação: 23/03/2004 Aprovado para publicação: 13/02/2006

\author{
1 - Médica Veterinária Autônoma \\ 2 - Departamento de Ciências Animais da Escola Superior de Agricultura de \\ Mossoró, Mossoró - RN \\ 3 - Departamento de Clínica e Cirurgia Veterinária da Faculdade de Ciências \\ Agrárias e Veterinárias da Universidade Estadual Paulista, Jaboticabal - SP \\ 4 - Departamento de Biociências da Universidade Federal do Rio Grande do \\ Norte, Natal - RN \\ 5 - Departamento de Morfologia e Fisiologia Animal da Faculdade de \\ Ciências Agrárias e Veterináriasda Universidade Estadual Paulista, \\ Jaboticabal - SP \\ 6 - Departamento de Cirurgia da Faculdade de Medicina Veterinária e \\ Zootecnia da Universidade de São Paulo, São Paulo - SP
}

\section{Resumo}

Palavras-chave: Anatomia.

Para conhecer a origem do nervo isquiático de mocós (Kerodon rupestris WIED,1820) junto aos forames intervertebrais e a musculatura envolvida em seu trajeto, foram utilizados 10 animais adultos, oriundos do Centro de Multiplicação de Animais Silvestres da Escola Superior de Agricultura de Mossoró (CEMAS-ESAM). Após o óbito natural, estes foram fixados em formol a 10\%, e foram dissecados para exposição e visualização do nervo isquiático. Os resultados foram expressos em percentual. Foram verificadas variações na quantidade de vértebras lombares e sacrais. Cinco animais (50\%) apresentaram sete vértebras lombares e três sacrais, dois $(20 \%)$ apresentaram sete vértebras lombares e quatro sacrais, e dois $(20 \%)$ apresentaram seis vértebras lombares e três sacrais. Um animal (10\%) apresentou seis vértebras lombares e quatro sacrais. Portanto, a origem do nervo foi diferenciada. Cinco animais $(50 \%)$ tiveram a participação de $\mathrm{L}_{7}, \mathrm{~S}_{1}, \mathrm{~S}_{2}$; dois animais $(20 \%) \mathrm{L}_{7}, \mathrm{~S}_{1}$, com pequena contribuição de $\mathrm{S}_{2}$. Dois animais $(20 \%)$, de $\mathrm{L}_{6}, \mathrm{~S}_{1}, \mathrm{~S}_{2}$; e um animal (10\%), de $\mathrm{L}_{6}, \mathrm{~S}_{1}$ com uma pequena contribuição de $S_{2}$. A última raiz do nervo isquiático em todas as suas origens, contribuiu para a formação da primeira raiz do nervo pudendo. Constatou-se que ao longo de seu trajeto os nervos isquiáticos cederam ramos para os músculos glúteo médio, glúteo profundo, glúteo surpeficial, emitindo ramos musculares para o bíceps femoral ou da coxa, e para os músculos semimembranoso e semitendinoso, que continua com um tronco calibroso, originando os nervos fibular lateralmente, medialmente o tibial e caudalmente o cutâneo sural plantar lateral.

\section{Introdução}

Os mocós (Kerodon rupestris WIED, 1820) pertencem à ordem Rodentia, família dos cavídeos e subfamília caviinae, possuindo habitat mais especializado em relação às outras formas caviinaes e ao gênero Kerodon, se assemelhando aos gêneros Cavia e Galea ${ }^{1}$.

Conforme Mendes ${ }^{2}$, os mocós por serem nativos do nordeste, são altamente adaptados às condições ecológicas regionais, 
como: calor, escassez de água e de alimentos principalmente nos períodos das grandes secas que assolam periodicamente a região do semiárido nordestino.

O mocó adulto mede aproximadamente $410 \mathrm{~mm}$ e pesa, em média, $800 \mathrm{~g}$. Tem habitat muito especial, constituído por afloramento de rochas, onde faz morada nas locas (pequenas grutas). Este roedor não habita regiões planas. É bastante dócil, sendo por isso facilmente caçado. Seus alimentos são folhas, brotos, ramos, frutos, cascas de árvores, raízes e tubérculos de arbustos de árvores da caatinga ${ }^{2,3}$.

O estudo destes animais contribui para o avanço das ciências morfológicas, além disso, revela a grande importância da fauna silvestre de cada região e isso tem favorecido a sua preservação e criações em cativeiro 4 .

O nervo isquiático é um dos principais nervos que compõem o plexo lombossacral do mocó $^{5}$. Considerando a importância anátomo-clínica do nervo isquiático, Cox, Breazile e Hoover ${ }^{6}$, comentaram que lesões nele resultam em paralisia parcial da musculatura caudal da coxa.

Observamos na literatura científica especializada, uma restrição aos trabalhos sobre este tema, principalmente em relação às descrições do comportamento do nervo isquiático em animais silvestres, este, portanto, vem a contribuir fornecendo bases morfológicas importantes para a conduta clinica de rotina, com estudo minuncioso do nervo isquiático, se tratando do maior nervo que compõe o plexo lombossacral, conhecendo sua disposição anatômica e a musculatura envolvida em seu percurso, para que não ocorram acidentes e ou, lesões iatrogênicas com o mesmo, como aplicações de medicações intramusculares profundas, ou até mesmo algum procedimento cirúrgico realizado no membro pélvico destes animais, sendo prática comum na clínica de pequenos animais.

Com isso, o objetivo central desta pesquisa é a localização do nervo isquiático no membro pélvico do mocó, quais músculos estão envolvidos e a contribuição desse estudo no que se refere à clínica de animais silvestres.

\section{Materiais e Métodos}

Os resultados que serão mostrados baseiam-se no exame do nervo isquiático de mocós (Kerodon rupestris), adultos, de diferentes idades, sendo cinco machos e cinco fêmeas, que vieram a óbito naturalmente, oriundos do Centro de Multiplicação de Animais Silvestres da Escola Superior de Agricultura de Mossoró (CEMAS/ESAM), sendo este criatório cientifico, autorizado com numero de registro (12.492-004) pelo Instituto Brasileiro do Meio Ambiente e Recursos Naturais Renováveis (IBAMA-RN), tendo como objetivo fomentar a pesquisa, formar e manter espécies que habitam a região do semi-árido nordestino.

Para fixação dos animais, a artéria carótida comum, foi canulada para a injeção da solução aquosa de formol a 10\%. Em seguida conservados na mesma solução por um período mínimo de 48 horas. A seguir foram realizadas dissecações para exposição do nervo isquiático assim como suas ramificações. O experimento foi realizado a olho nu e quando necessário utilizou-se uma lente de aumento em 10x (lupa), para melhor visibilização dos nervos.

Após a exposição de todo nervo isquiático foi colocado sobre o mesmo algodão embebido com peróxido de hidrogênio a 20 volumes, permanecendo por 12 horas seguidas, para o clareamento do nervo isquiático, facilitando assim sua visibilização. Dessa forma, registrou-se os dados obtidos através de desenhos esquemáticos. As modalidades encontradas foram agrupadas em tabelas.

Estatisticamente, por ser uma amostra pequena, optou-se por uma análise simplificada, a qual se resume em analisar os dados de forma descritiva em termos de percentagem simples.

\section{Resultados e Discussão}

\section{Quanto ao número de vértebras:}

Foram verificadas variações na quantidade de vértebras lombares e sacrais do Mocó (Kerodon rupestris WIED, 1820) nas 
Tabela 1 - Freqüência das variações no número de vértebras lombares e sacrais do mocó. Mossoró, 2004

\begin{tabular}{cc}
\hline Fórmula vertebral & Freqüência \\
\hline $\mathrm{L}_{7} \mathrm{~S}_{3}$ & $50,00 \%$ \\
$\mathrm{~L}_{7} \mathrm{~S}_{4}$ & $20,00 \%$ \\
$\mathrm{~L}_{6} \mathrm{~S}_{3}$ & $20,00 \%$ \\
$\mathrm{~L}_{6} \mathrm{~S}_{4}$ & $10,00 \%$ \\
\hline
\end{tabular}

Tabela 2 - Freqüência das variações no número de vértebras lombares e sacrais do mocó em relação à origem do nervo isquiático. Mossoró, 2004

\begin{tabular}{cc}
\hline Fórmula vertebral & Freqüência \\
\hline$L_{7} S_{1} S_{2}$ & $50,00 \%$ \\
$L_{7} S_{1}$ & $20,00 \%$ \\
$L_{6} S_{1} S_{2}$ & $20,00 \%$ \\
$L_{6} S_{1}$ & $10,00 \%$ \\
\hline
\end{tabular}

Tabela 3 - Freqüência das distribuições do nervo isquiático no mocó pela musculatura do membro pélvico. Mossoró, 2004

\begin{tabular}{cc}
\hline Distribuição & Freqüência \\
\hline Músculo glúteo médio & $100,00 \%$ \\
Músculo glúteo profundo & $100,00 \%$ \\
Músculo glúteo surpeficial & $100,00 \%$ \\
Músculo bíceps femoral ou bíceps da coxa & $100,00 \%$ \\
Músculo semimembranoso & $100,00 \%$ \\
Músculo semitendinoso & $100,00 \%$ \\
\hline
\end{tabular}

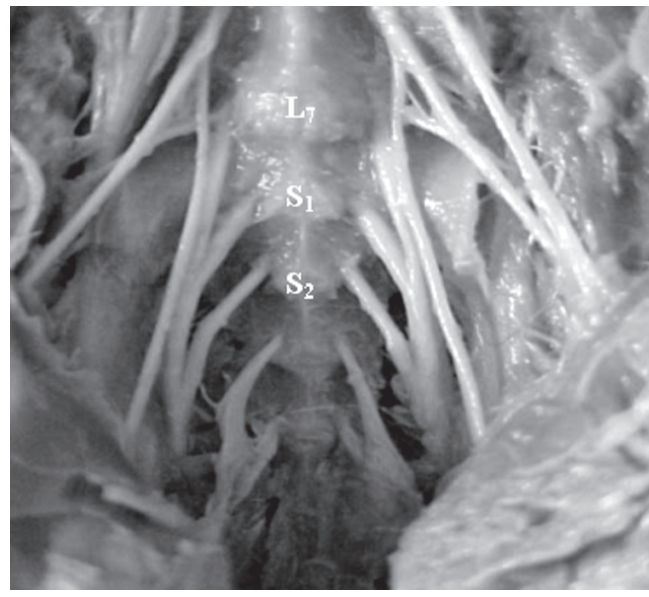

Figura 1 - Origem do nervo isquiático $\mathrm{L}_{7} \mathrm{~S}_{1} \mathrm{~S}_{2}$

10 amostras quando analisadas individualmente. A contagem foi realizada após dissecação da musculatura epaxial e sublombar, sendo considerada como a primeira vértebra lombar a que estivesse

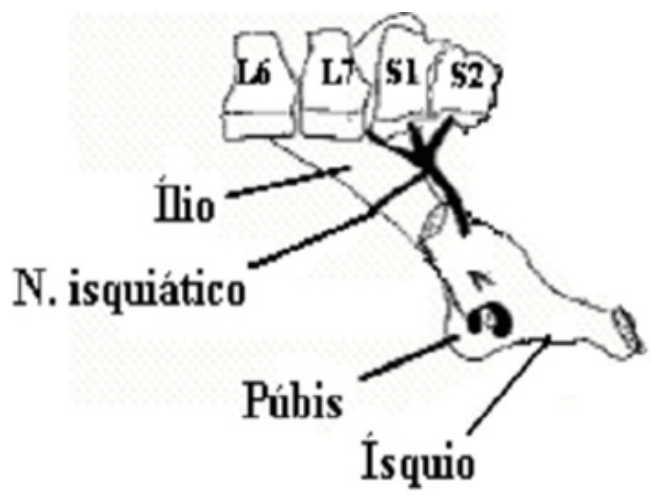

Figura 2-Vista lateral da origem do nervo isquiático $\mathrm{L}_{7} \mathrm{~S}_{1} \mathrm{~S}_{2}$

caudalmente a ultima costela. Constatou-se em cinco animais $(50 \%)$ a presença de sete vértebras lombares e três vértebras sacrais; dois animais (20\%) apresentaram sete vértebras lombares e quatro sacrais; outros 


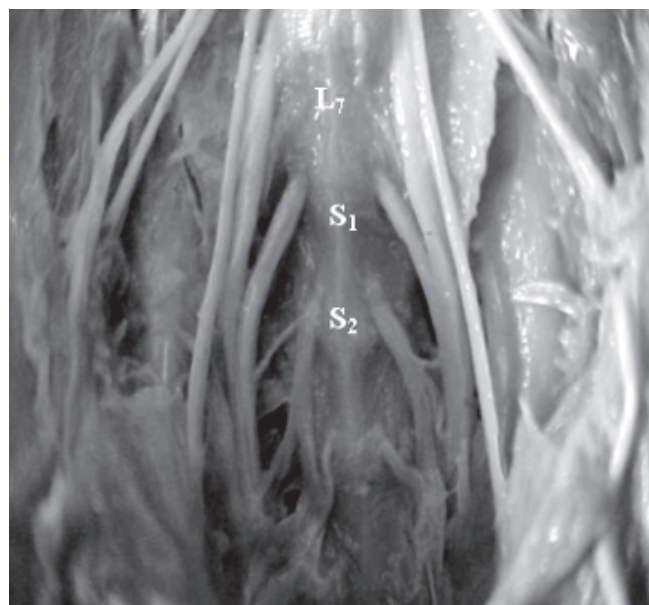

Figura 3-Origem do nervo isquiático $\mathrm{L}_{7} \mathrm{~S}_{1}$ (pequena contribuição de $\mathrm{S}_{2}$ )

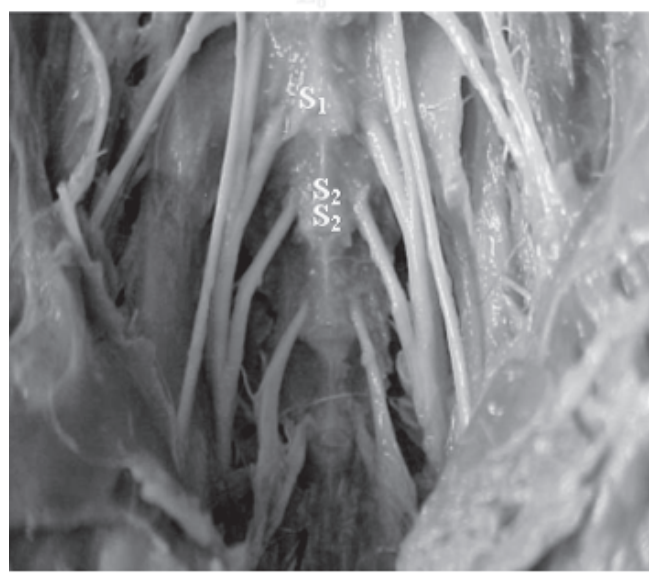

Figura 5 - Origem do nervo isquiático $\mathrm{L}_{6} \mathrm{~S}_{1} \mathrm{~S}_{2}$

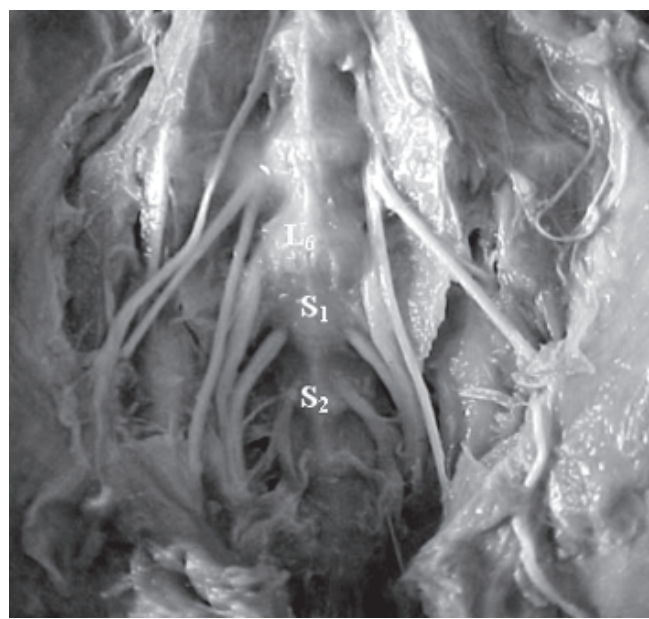

Figura 7-Origem do nervo isquiático $\mathrm{L}_{6} \mathrm{~S}_{1}$ (pequena contribuição de $\mathrm{S}_{2}$ )

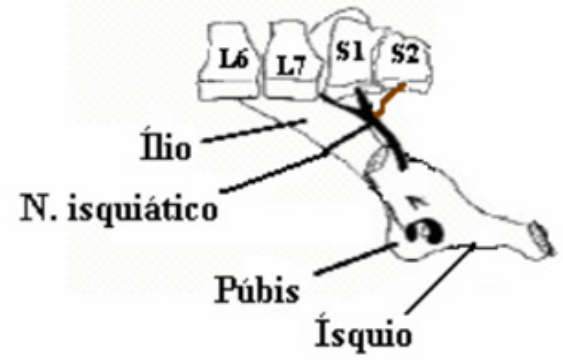

Figura 4 - Vista lateral da origem do nervo isquiático $\mathrm{L}_{7} \mathrm{~S}_{1}$ (pequena contribuição $S_{2}$ )

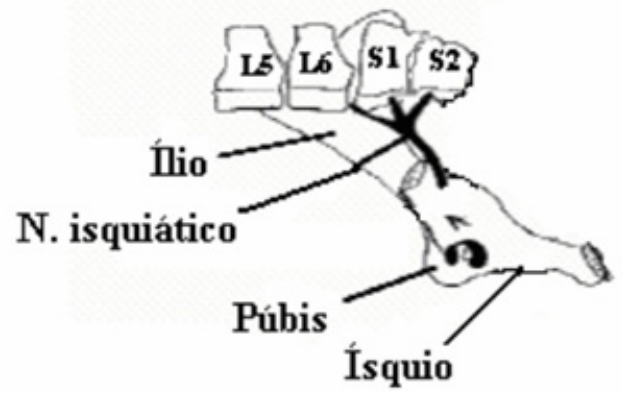

Figura 6 - Vista lateral da origem do nervo isquiático $\mathrm{L}_{6} \mathrm{~S}_{1} \mathrm{~S}_{2}$

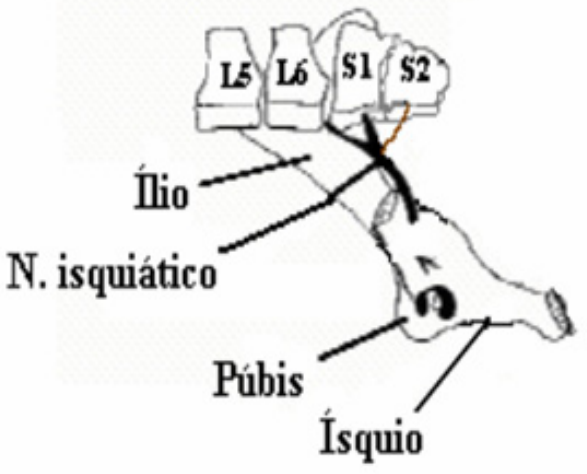

Figura 8 - Vista lateral da origem do nervo isquiático $\mathrm{L}_{7} \mathrm{~S}_{1}$ (pequena contribuição $S_{2}$ ) 


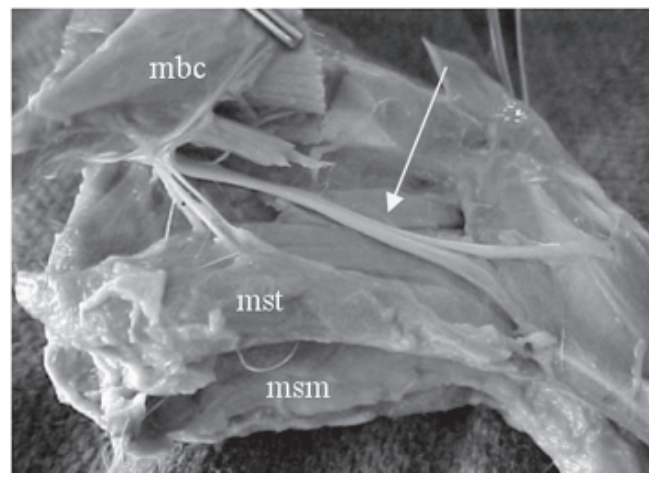

Figura 9-Musculatura envolvida no trajeto do nervo isquiático mbc- músculo bíceps da coxa mst- músculo semitendinoso msm- músculo semimembranoso

dois $(20 \%)$ possuíam seis vértebras lombares e três sacrais e em apenas um animal (10\%) foi encontrado seis vértebras lombares e quatro sacrais. O número de vértebras lombares e sacrais no mocó, apesar da pequena amostra, apresentou-se bastante variável, o que está de acordo com Pirlot ${ }^{7}$ ao afirmar que o número de vértebras varia entre as espécies e dentro da mesma espécie. Torrey $^{8}$ também descreve a possibilidade de variação numérica, mas afirma que o número de vértebras lombares aumenta numa relação inversa a quantidade de vértebras torácicas. Dessa forma o número de vértebras torácicas, somada as lombares permanece constante. Dentre os comportamentos encontrados, $\mathrm{O} \mathrm{L}_{7} \mathrm{~S}_{3}$ foi mais freqüente $(50 \%)$, este é semelhante ao padrão descrito para cães, enquanto o tipo $\mathrm{L}_{7} \mathrm{~S}_{4}$ também foi descrito para coelhos ${ }^{9}$ e os tipos $\mathrm{L}_{6} \mathrm{~S}_{3}$ e $\mathrm{L}_{6} \mathrm{~S}_{4}$ não são mencionados pelos tratadistas para as espécies domésticas. A fórmula vertebral da coluna lombar e sacral dos mocós estudados pode ser observada na tabela 1 .

\section{Origem das raízes do nervo isquiático:}

Com a variação no número de vértebras lombares e sacrais, a origem das raízes do nervo isquiático se apresentaram distintas comparando os mesmos dentro da espécie, junto aos forames intervertebrais ou vertebrais laterais. Já os nervos isquiáticos direito e esquerdo do mesmo, apresentaram simetria em relação a sua origem em todos os animais estudados (100\%), se originando dos ramos ventrais do sexto e sétimo nervos espinhais lombares e do primeiro e segundo nervos espinhais sacrais. Foram encontrados quatro tipos de origem do nervo isquiático nos mocós no antímero esquerdo e direito. Cinco animais (50\%), tiveram a participação de $\mathrm{L}_{7}, \mathrm{~S}_{1}, \mathrm{~S}_{2}$ (Figura 1 e Figura 2); dois animais $(20 \%) \mathrm{L}_{7}, \mathrm{~S}_{1}$, existindo uma pequena contribuição de $\mathrm{S}_{2}$ (Figura 3 e Figura 4); dois animais $(20 \%)$ de $\mathrm{L}_{6}, \mathrm{~S}_{1}, \mathrm{~S}_{2}$ (Figura 5 e Figura $6)$; e um animal $(10 \%)$, de $\mathrm{L}_{6}, \mathrm{~S}_{1}$ e uma pequena contribuição de $\mathrm{S}_{2}$ (Figura 7 e Figura 8). A última raiz do nervo isquiático em todas as suas origens, contribui para a formação da primeira raiz do nervo pudendo. Confirmado por Lacerda ${ }^{5}$, quando estudou o plexo lombossacral do mocó, relatando que o nervo isquiático, possui suas raízes a partir dos ramos ventrais do sexto e sétimo nervos lombares, ou seja, os dois últimos nervos lombares e dois primeiros sacrais. A formula vertebral da coluna lombar e sacral dos mocós, em relação a sua origem pode ser observada na tabela 2 .

\section{Distribuição do nervo isquiático no mocó}

No tocante a sua distribuição, constatou-se que em todos os animais estudados, o nervo isquiático ao longo do seu trajeto fornecia ramos para os músculos glúteo médio direito e esquerdo, glúteos profundos direito e esquerdos (nervo glúteo cranial), glúteos surpeficial direito e esquerdo (nervo glúteo caudal), em seguida emitiu ramos musculares (Figura 9) para o bíceps femoral ou bíceps da coxa e para os músculos semimembranoso e semitendinoso e se continua com um tronco calibroso caudolateral a articulação do joelho, se dividindo em um ramo cranial que se segue na face lateral da coxa originando o nervo fibular, medialmente o tibial e caudalmente o cutâneo sural plantar lateral. Quanto à distribuição dos ramos dos nervos isquiáticos, evidenciou-se que as observações do presente estudo estiveram de acordo com 
os informes de Cox, Breazile e Hoover ${ }^{6}$ e Bruni e Zimmerl ${ }^{10}$, nos quais os referidos nervos supriram os músculos das regiões glútea e da coxa. A disposição do nervo isquiático as características do mesmo se apresentaram de forma semelhante aos citados pelo tratados de anatomia veterinária referentes aos animais domésticos Ghoshal ${ }^{11}$, descreve que o nervo isquiático passa sobre a chanfradura isquiática maior, medialmente ao músculo glúteo médio, músculo glúteo profundo e ainda medialmente ao músculo semitendinoso, semimembranoso, músculo adutor da coxa e ao músculo bíceps da coxa. A distribuição do nervo isquiático em mocós assemelha-se ao comportamento observado em cães ${ }^{12,13}$. Primeiramente, emite ramos ditos musculares para a região glútea e músculo bíceps femoral, em seguida segue seu curso entre os músculos semimembranoso e semitendinoso, o que permite deduzir que uma área segura para aplicações medicamentosas intramusculares em mocós seria a região do músculo semimembranoso ou mesmo no semitentinoso na sua face caudal. A freqüência das distribuições dos nervos isquiáticos dos mocós estudados em relação a musculatura envolvida podem ser observado na tabela 3 .

\section{Conclusões}

O estudo do comportamento anatômico do nervo isquiático em mocós permitiu descrever suas características em relação a sua origem, observando seu trajeto e suas ramificações.

Foram encontradas variações no número de vértebras lombares e sacrais influenciando assim na origem do nervo isquiático.

Foi possível constatar que na espécie, o nervo isquiático emite ramos cutâneos, proximal e distal, e um ramo próprio para os músculos glúteo médio, glúteo profundo (nervo glúteo cranial), glúteo superficial (nervo glúteo caudal), além dos ramos musculares para o bíceps da coxa e para os músculos semimembranoso e semitendinoso e que se continua com um tronco calibroso caudal lateral a articulação do joelho, sendo este o nervo fibular lateralmente, medialmente o tibial e caudal o nervo cutâneo sural plantar lateral.

\section{Ischiatic nerve anatomy in mocós (Kerodon rupestris WIED, 1820) applicable to clínic of wild animals}

\begin{abstract}
To know the origin of the ischiatic nerve in mocos (Kerodon rupestris Wied,1820) near by intervertebral forames and the muscling belonging to its routes were used 10 adult animals, from CEMAS-ESAM. After natural obit, they were fixed in formol $(10 \%)$ and dissected to exposition and to singt of the ischiatic nerve. The results were indicated in percentage. Variations in the quantity of the lumber and sacral vertebras nere observed, five animals $(50,00 \%)$ reveled seven lumbar vertebras and three sacral ones; two animals recrealed seven lumbar vertebras and four sacral ones, and two animals reveled six lumbar vertebras and three sacral ones. An animal (10,00\%) revealed six lumbar vertebras and four ones. Therefore, the origin of the nerve was differentiated five animals $(50,00 \%)$ had the participation of $\mathrm{L}_{7}, \mathrm{~S}_{1}, \mathrm{~S}_{2}$; two animals $(20,00 \%)$ with $\mathrm{L}_{7}, \mathrm{~S}_{1}$; and a little part of $\mathrm{S}_{2}$. Two animals $(20,00 \%)$ with $\mathrm{L}_{6}, \mathrm{~S}_{1}, \mathrm{~S}_{2}$, and an animal $(10,00 \%)$ with $\mathrm{L}_{6}, \mathrm{~S}_{1}$, and a little part of $\mathrm{S}_{2}$. The last root of the ischiatic nerve in all its origins, contribute to the constitution of the first root of pudental nerve. It was verified that in all its route, the ischiatic nerves $(100,00 \%)$ ceded branches to the muscles: medial gluteus, deep gluteus, superficial gluteus, emiting
\end{abstract}

Key-words: Anatomy. Ischiatic nerve. Kerodon rupestris. 
muscular branches to the femoral biceps or to thigh, and to the semimembranous and semi-tendinous muscles, that is continuous with a high calibre trunk, originating the fibular nerve(sideways), the tibial nerve(medial) and the lateral plantar sural cutaneous nerve (caudal).

\section{Referências}

1 LANCHER JR, T. E. The comparative social behavior of Kerodon Rupestris and galea spixii and the evolution of behaviour in the caviidae. Bulletin of Museum Natural History, n. 17, p. 1-71, 1981.

2 MENDES, B. V. Plantas e animais para o nordeste. Rio de Janeiro: Globo, 1987. 167 p.

3 MENDES, B. V. Alternativas tecnológicas para a agropecuária do semi-árido. São Paulo: Nobel, 1985. $171 \mathrm{p}$.

4 GONÇALVES, I. P. D. Medicina de animais silvestres na clinica veterinária. A Hora Veterinária. Porto Alegre. v. 9, n. 49, p. 37-39, maio/jun 1989.

5 LACERDA, P. M. O. Estudo anatômico aplicado à origem do plexo lombossacral em mocó (Kerodon rupestris) criados em cativeiro no semi-árido nordestino. Mossoró: ESAM, 2003.

6 COX, W. S; BREAZILE, J. E; HOOVER, T. R. Surgical and anatomic study of calving paralysis. American Journal of Veterinary Research, v. 36, n. 4, p. 427430, 1975.

7 PIRLOT, P. Morfologia evolutiva de los cordados. Barcelona: Omega, 1976. 966 p.

FRADSON, R. R. Anatomia e fisiologia dos animais domésticos. 2. ed. Rio de Janeiro: Guanabara, 1979.

8 TORREY, T. W. Morfogenesis de los vertebrados. 3. ed. México: Limusa, 1978. 576 p.

9 MORANDINI, C. Zoologia. 4. ed. São Paulo: Nobel, 1971. v. 4, 421 p.

10 BRUNI, A. C; ZIMMERL,V. Anatomia degli animali domestici. 2. ed. Milano: Casa Editrici Dr Francesco Vallardi, 1977. v. 2, 736 p.

11 GROSHAL, N. G. Nervos espinhais. In: GETTY, R. Sisson/Grossman: anatomia dos animais domésticos. 5. ed. Rio de Janeiro: Guanabara Koogan, v. 1, 1986, p 1052-1077.

12 DYCE, K. M; SACK, W. O; WENSING, C. J. G. Tratado de Anatomia Veterinária. 2. ed. Rio de Janeiro: Guanabara, 1997. 663 p.

13 EVANS, H. E; DE LAHUNTA, A. Guia para dissecção do cão. 3. ed. Rio de Janeiro: Guanabara, 1994. 206 p. 